\title{
TUBERCULOSIS DIAGNOSIS;
}

DELAY IN TUBERCULOSIS DIAGNOSIS AND TREATMENT OF PATIENTS ATTENDING TB DOTS CENTRE IN TERTIARY CARE HOSPITAL OF LAHORE.

1. MBBS, Masters in Hospital Management

(University of Health Sciences) Emergency Medical Office, Jinnah Hospital, Lahore.

2. MBBS, DMCH, FCPS Head Department of Community Medicine Independent Medical College Faisalabad.

3. MBBS, FCPS

Assistant Professor,

Department of Community Medicine Khawaja Muhammad Safdar Medical College, Sialkot.

4. MBBS

FCPS Trainee

Institute of Public Health, Lahore

5. MBBS, MPH

Associate Professor Community Medicine

Independent Medical College

Faisalabad.

Correspondence Address:

Taskeen Zahra

965-C, Canal view Housing Society,

Multan Road, Lahore.

dr.taskeenzahra@yahoo.com

Article received on:

18/05/2017

Accepted for publication:

13/04/2018

Received after proof reading:

02/06/2018
Iram Nawaz', Rabia Arshed Usmani², Taskeen Zahra ${ }^{3}$, Asima Asif ${ }^{4}$, Shahbaz Baig ${ }^{5}$

ABSTRACT... Background: Delay in diagnosis of Tuberculosis (TB) and initiation of antitubercular treatment (ATT) contributes to more severe disease manifestations in the individual and higher disease transmission in the community. Objective: To find out the delays in diagnosis and treatment of TB patients and to describe determinants related to these delays. Study Design: Cross-sectional descriptive study. Setting: TB Directly Observed Treatment Short course (DOTS) Center of Jinnah Hospital, Lahore. Period: July to September 2013. Methods: 373 tuberculosis patients attending TB Directly Observed Treatment Short course (DOTS) Center of Jinnah Hospital, Lahore were included using simple random sampling. Delay was then categorized into low delay and high delay depending upon the median of total delay which was of 97 days. Results: It was concluded that the total median diagnostic and treatment delay related to both patients as well as health system was 97 days. Results revealed that about $55.7 \%$ patients had high total delay (delay > median) and $44.3 \%$ patients had low total delay. Among those patients with high delay, $58.7 \%$ were aged above 35 years, $81.4 \%$ were females, $96.4 \%$ were illiterate, $54.8 \%$ were living in rural areas, $76.7 \%$ travelled greater than $5 \mathrm{~km}$ to reach the nearest health facility and $56.9 \%$ patients had more than one health seeking encounters with health care professionals before initial diagnosis. Conclusion: Current study, therefore, highlights the delays in diagnosis, treatment and the determinants of delay showing health system related diagnostic and treatment delay being the main contributor to the total delay. More than half of the patients with TB showed a delay in initiation of treatment. Efforts should be made to minimize health system related delays. Local private practitioners should also be taken on board in combating tuberculosis.

Key words: $\quad$ Tuberculosis, Treatment Delay.

Article Citation: Nawaz I, Usmani RA, Zahra T, Asif A, Baig S. Delay in tuberculosis diagnosis and treatment of patients attending TB Dots Centre in Tertiary Care Hospital of Lahore. Professional Med J 2018; 25(6):914-919.

DOI:10.29309/TPMJ/18.4955

\section{INTRODUCTION}

Tuberculosis (TB) is an infectious disease caused by bacterium Mycobacterium tuberculosis that mostly affects the lungs. ${ }^{1}$ TB spreads from person to person through the air. ${ }^{2}$ Tuberculosis remains a worldwide public health problem. $^{3}$ World Health Organization (WHO) declared TB a global emergency in 1993 in recognition of its growing influence as a public health problem. ${ }^{4}$ In 2015, 10.4 million people fell ill with TB and 1.8 million died from the disease (including 0.4 million among people with HIV). Over 95\% of TB deaths occur in low- and middle-income countries. Six countries account for $60 \%$ of the total, with India leading the count, followed by Indonesia, China, Nigeria, Pakistan and South Africa. ${ }^{2}$ Pakistan ranks fifth among TB high-burden countries worldwide. It accounts for $61 \%$ of the TB burden in the WHO Eastern Mediterranean Region. ${ }^{5}$ Following the staggering burden of TB, the National TB Control Programme (NTP) Pakistan adopted DOTS (Directly Observed Treatment, Short course) strategy in 1995. With an early diagnosis and prompt treatment as its mainstay.

Delay in diagnosis of TB is delay at patients and health system's delay. Patient delay which is the time interval between the onset of symptoms and first seeking care at a health care provider and the health system (system delay) is the time interval between seeking care at a health care provider and diagnosis of TB. ${ }^{11,12}$ These delays are reflected either as patient delays in seeking care or health care provider delays in making 
the diagnosis or starting treatment or both. ${ }^{13}$ To improve the strategy of TB DOTS, it is necessary to understand the determinants and various aspects of these delays. ${ }^{8}$ Various studies had been conducted to assess the health care seeking behavior and delay in treatment of pulmonary TB patients and to identify the determinants of the delay in treatment of pulmonary TB. Lock and partners (2011) conducted a study in Indonesia to assess the determinants related to delay among TB suspects and concluded a median patient delay of 14 days. The study also showed that most of patients were visiting a private health care provider firstly. Major determinant influencing the patient delay in the study was the travel time as the less travel time was significantly associated with shorter patient delay ${ }^{8}(P \leq 0.05)$. A study conducted in Rawalpindi at National TB Centre (NTC) showed a median delay of 56 days (8 weeks) in which age, cough and fever were the main significant determinants. Study conducted by Ukwaja and associates (2013) in Nigeria showed total median delay of 11 weeks, the patient diagnostic delay of 8 weeks and healthcare system(HS)delay of 3 weeks. The study also showed that determinants associated with increased patient delay were old age, longer walking distance to public facility, urban residence and an initial visit to a non-NTP provider. ${ }^{14}$

The magnitude and factors associated with the delay fluctuates in developed and developing countries the dearth of literature regarding the delay in diagnosis and treatment of TB has initiated the present study to find out the frequency of delay in diagnosis as well as treatment of T.B patients attending TB DOTS Centres of Jinnah Hospital, Lahore and to describe the determinants related to these delays.

\section{METHODS}

It was a cross sectional descriptive study conducted during July to September 2013 at T.B. DOTS Center of Jinnah Hospital, Lahore, which is a 1250 bedded teaching hospital of Punjab. The sample size of 373 patients was taken by using systematic random sampling. First patient was selected randomly and then every $3^{\text {rd }}$ patient was taken. Patients with newly diagnosed TB for first time, having smear positive and age above 15 years were included in the study while those with smear negative, extra pulmonary TB and TB relapses and defaulters in the past were excluded. Semi-structured, pretested questionnaire covering all variables was used to record the response of the respondents. Data was collected after receiving permission from the hospital authorities and concerned TB DOTS Center authorities.

Delay was first categorized into patient and healthcare delay. Patient related delays included diagnostic delay which was the time interval between appearance of symptoms suggestive of pulmonary tuberculosis and their first contact with a health care facility. Healthcare system delay included both health system related diagnosis delay and treatment delay. Diagnostic delay was the time interval between first contact with the facility and confirmation of diagnosis. Health care was time interval between confirmation of diagnosis and initiation of anti-tuberculosis treatment. Total delay was the sum total of patient and health system delays. Data was analyzed by using SPSS 16.0.Delay i.e. diagnostic, treatment and total delay was counted in days. Median value was computed below and above the median delays respectively. Data was then further categorized as low or high delay. Delay less than or equal to median of data was taken as low delay and value of delay above median were taken as high delay and it is presented in the form of frequencies and percentage.

\section{RESULTS}

Table-I showed that among 373 patients, total median diagnostic and treatment delay related to both patients as well as health system was 97 days. Table-I describes delay for TB patients at different stages. As far as patient related diagnostic delays is concerned, result shows that among 373 patients, 150(40.85\%) had low delay $(\leq \mathrm{MD})$ and majority 221 (59.2\%) had high delay (>MD). Table-Il describes determinants for total delays. Among those patients who had high delay, $58.7 \%$ aged above 35 years, $81.4 \%$ were females, and $60.4 \%$ were rural residents. It was also found that within high 
delays patients, $96.4 \%$ were illiterate, $57.0 \%$ were married, $66.5 \%$ were manual workers or clerks, $94.6 \%$ had income less than 10,000 rupees and $87.7 \%$ had visited first level care facility. $56.6 \%$ of those who had diagnosis at TB center of secondary level health care (DHQ/THQ) had high delay and $59.6 \%$ of high delayed patients visited more than one health care professionals before their initial diagnosis and the distance of accessible health facility was more than $5 \mathrm{~km}$ in $76.7 \%$ of patients showing high delay.

\begin{tabular}{|c|c|c|}
\hline Characteristics & Frequency & Percentages (\%) \\
\hline \multicolumn{3}{|c|}{ Patient related diagnostic delay(Median delay=9days) } \\
\hline Low delay $(\leq \mathrm{MD})$ & 152 & 40.8 \\
\hline High delay (>MD) & 221 & 59.2 \\
\hline \multicolumn{3}{|c|}{ Health System related diagnostic delays (Median delay $=74$ days) } \\
\hline Low delay $(\leq \mathrm{MD})$ & 76 & 20.4 \\
\hline High delay (>MD) & 297 & 80 \\
\hline \multicolumn{3}{|c|}{ Diagnostic delay(total median delay $=73$ days) } \\
\hline Low delay $(\leq \mathrm{MD})$ & 62 & 16.6 \\
\hline High delay (>MD) & 311 & 83.4 \\
\hline \multicolumn{3}{|c|}{ Treatment delay(Median delay $=4$ days) } \\
\hline Low delay $(<\mathrm{MD})$ & 164 & 44.0 \\
\hline High delay (>MD) & 209 & 56.0 \\
\hline \multicolumn{3}{|c|}{ Health system delay(Median delay $=87$ days) } \\
\hline Low delay $(\leq \mathrm{MD})$ & 167 & 44.8 \\
\hline High delay $(>M D)$ & 206 & 55.2 \\
\hline \multicolumn{3}{|c|}{ Total delay(median delay $=97$ days) } \\
\hline Low delay $(\leq \mathrm{MD})$ & 165 & 44.3 \\
\hline High delay (>MD) & 208 & 55.7 \\
\hline
\end{tabular}

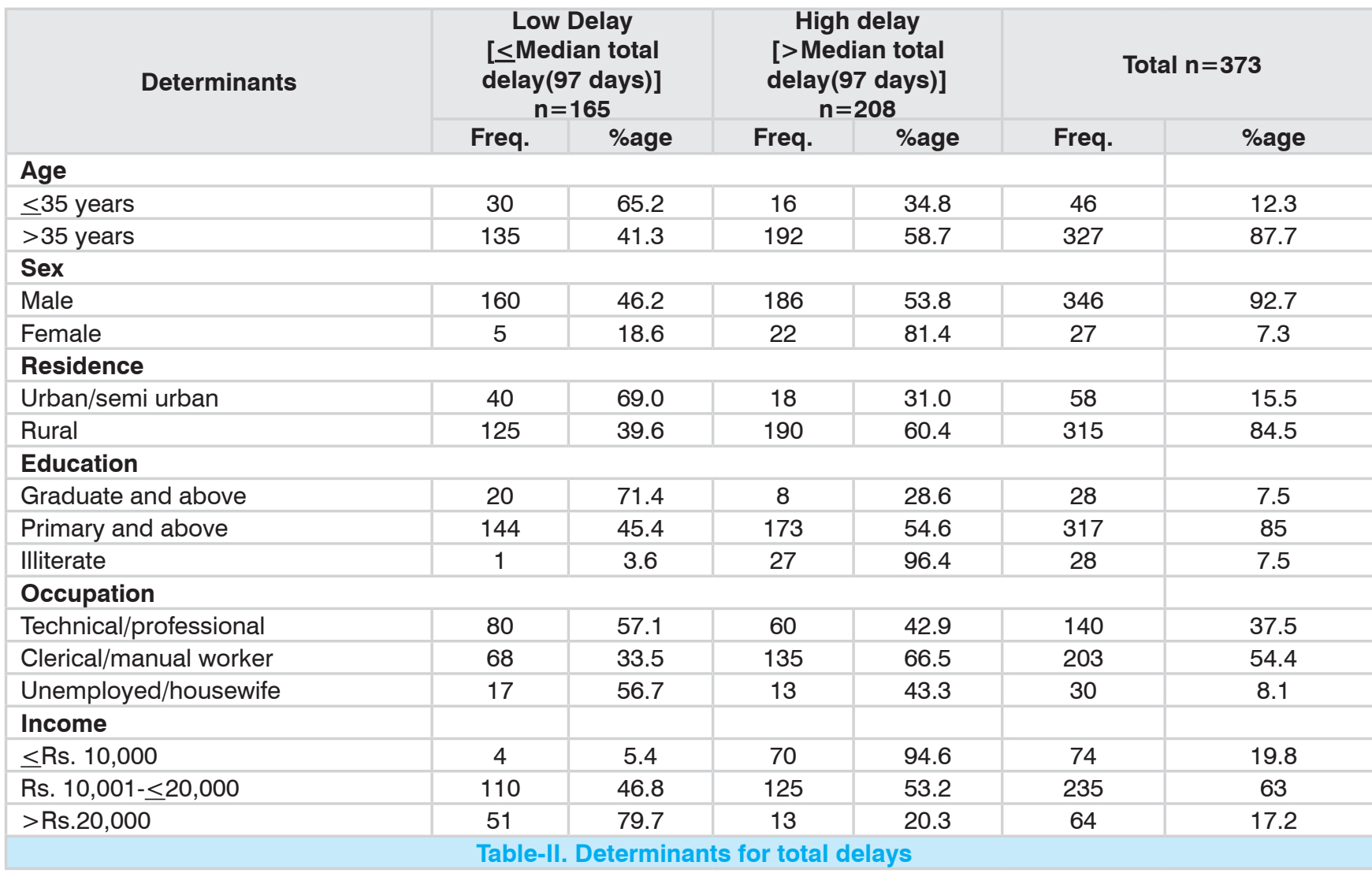




\begin{tabular}{|c|c|c|c|c|c|c|}
\hline \multirow[t]{2}{*}{ Characteristics } & \multicolumn{2}{|c|}{$\begin{array}{c}\text { Low Delay } \\
\left(<M D^{\star}\right) \\
n=165\end{array}$} & \multicolumn{2}{|c|}{$\begin{array}{l}\text { High delay } \\
\left(>M^{\star}\right) \\
n=208\end{array}$} & \multicolumn{2}{|c|}{ Total $n=373$} \\
\hline & Freq. & \%age & Freq. & \%age & Freq. & \%age \\
\hline \multicolumn{7}{|l|}{ Marital status } \\
\hline Single & 19 & 57.6 & 14 & 42.4 & 33 & 8.8 \\
\hline Married & 46 & 43.0 & 94 & 57.0 & 340 & 91.2 \\
\hline \multicolumn{7}{|c|}{ First health care facility visited before diagnosis } \\
\hline Private clinic or hospital & 4 & 33.4 & 8 & 66.6 & 12 & 3.3 \\
\hline Public hospital & 140 & 43.2 & 169 & 57.8 & 324 & 86.7 \\
\hline $\begin{array}{l}\text { Hakeem/pharmacist/ } \\
\text { dispenser }\end{array}$ & 6 & 16.2 & 31 & 83.8 & 37 & 10 \\
\hline \multicolumn{7}{|c|}{ Facility where diagnosis was made } \\
\hline TB Centre at PHC & 7 & 50.0 & 7 & 50.0 & 14 & 3.7 \\
\hline $\begin{array}{l}\text { TB Centre at secondary Level } \\
\text { Health care } \\
\text { (DHQ/THQ) }\end{array}$ & 135 & 43.4 & 176 & 56.6 & 311 & 83.3 \\
\hline $\begin{array}{l}\text { TB Centre at Tertiary Care } \\
\text { Hospital }\end{array}$ & 23 & 48.0 & 25 & 52.0 & 48 & 13 \\
\hline \multicolumn{7}{|c|}{ Number of health seeking encounters with HCP before initial diagnosis } \\
\hline 1 & 54 & 55.1 & 44 & 44.9 & 98 & 26.2 \\
\hline$>1$ & 111 & 40.4 & 164 & 59.6 & 275 & 73.8 \\
\hline \multicolumn{7}{|c|}{ Accessibility to health care facility } \\
\hline$\leq 5 \mathrm{~km}$ & 118 & 69.0 & 53 & 31.0 & 171 & 45.8 \\
\hline$>5 \mathrm{~km}$ & 47 & 23.3 & 155 & 76.7 & 202 & 54.2 \\
\hline
\end{tabular}

\section{DISCUSSION}

This study disclosed dreadful long median total delay is 97 days while the study done by Saqib (2011) showed a better scenario of median delay of 56 days..$^{15}$ The difference between the delay duration can be attributed to the fact that Saqib (2011) have conducted the study in National Tuberclosis Center, Rawalpindi, a specialized facility for the treatment of Tuberculosis, while this study was carried out in a Government Hospital providing multiple facilities along with emergency care. Study conducted by Ukjawa and associates (2013) showed median delay of 78 days which is also less than this study. ${ }^{14} \mathrm{~A}$ major reason from deviation from Ukjawa study is due to the fact this study is carried out in urban hospitals where patients from far flung areas come for treatment as compared to the rural hospitals which were taken as sample in Ukjawa's research where only local population has considered. ${ }^{14}$ While study conducted by Qureshi and coworkers (2008) showed median total delay of 90 days which is comparable to the delay showed by our study because of methodology like selection of hospitals. ${ }^{16}$
It is important to mention here that among major determinants of high delay in this study, majority of patients were more than 35 years of age which is very similar to the results shown by Ukjawa and associates. ${ }^{14}$ This displays that delay increases with increasing age. In this study, out of patients who had high delays, $81.4 \%$ were females whereas in the studies of Ukjawa, a large majority of patients were males. This may be attributed to the cultural norms of the females regarding their treatment, despite the fact that tuberculosis is more prevalent in females in Pakistan. ${ }^{5}$ This study shows that among high delay patients, majority were rural residents while Ukjawa's study showed high delay in urban patients with high delay was among those patients who had more than $5 \mathrm{~km}$ accessibility to health facility. ${ }^{14}$ Lack of facilities at rural areas and dysfunctional primary health care facilities in Pakistan compel people to travel to urban areas for health related issues adding to delays in seeking care making inaccessibility a major determinant too.

It is also found that within high delay patients, majority were illiterate which is very similar to the results of Ukjawa's study. This shows that a 
good educational status plays a significant role in health seeking behavior of patients. Current study, therefore, highlights the delays in diagnosis, treatment and the determinants of thesedelay showing health system related diagnostic and treatment delay being the main contributor to the total delay.

\section{CONCLUSION:}

It can be concluded from this study that the major determinants of high delay were age above 35 years, female gender, illiteracy, rural residence, manual/clerical work, low and middle income group, public facility visited before diagnosis, diagnosis related delay by health system, more than one health care professional visited, greater than $5 \mathrm{~km}$ accessibility of health facility were the major determinants of high delay. Strategy to reduce patient and health system delays should be made. Private practitioners and local traditional healers should also be taken on board through public private mix (PPM) together with awareness campaign allowing people at large to recognize their symptoms for combating tuberculosis. Ending the TB epidemic by 2030 is among the health targets of the newly adopted Sustainable Development Goals.

Copyright@ 13, Apr 2018.

\section{REFERENCES}

1. Schiffman G. What is TB. online 2011 assessed on 19 NOV 2013.

2. WHO, World Health Organization. Tuberculosis 2017 assessed on 21 September 2017.

3. ParkK. Tuberculosis: Preventive and social medicine, $25^{\text {th }}$ ed. Jabalpur (India): Banarasidas Bhanot; 2005, pp.643-660.

4. WHO, World Health Organization. Strategyamd framework for effective tuberculosis control. Guidelines for National Programs $3^{\text {rd }}$ ed. Geneva: WHO; 2003, pp.11-17.

5. WHO, World Health Organization. Pakistan: Tuberculosis [online] 2013 [cited on 2013 Nov.20]. Available from:http://www.emro.who.int/pak/programs/ stop-tuberculosis.html.
6. Jabbar A, Haider M. Anti-tuberculosis treatment: General physicians approach. Professional Med J 2007; 14:528-530.

7. PATBA, Pakistan Anti Tuberculois Association. National TB control Program Pakistan [online] 2013 [cited on 2013 Nov. 21]. Available from: http://www.patba.org/ ntp.htm.

8. Lock WA, Ahmad RA, Ruiter RAC, van der Werf MJ, Bos AER, Mahendradhata Y, etal. Patient delay determinants for patients with suspected tuberculosis in Yogyakarta province, Indonesia. Trop Med Int Health 2011; 16:1501-1510.

9. Mefsin MM, Newell JN, Walley JD, Gessessew A, Madeley RJ. Delayed consultation among pulmonary tuberculosis patients: A cross sectional study of 10 DOTS districts of Ethiopia. BMCpubl Health 2009; 9:53.

10. Fatiregun $A A$, Ejeckam CC. Determinants of patient delay in seeking treatment among pulmonary tuberculosis cases in a government specialist hospital in Ibadan, Nigeria. Tanazania $\mathrm{J}$ health Res 2010; 12:1-9.

11. Bassili A, Seita A, Baghdadi S, AIAbsi A, Addilail, Agboatwalla $M$, etal. Diagnostic and treatment delay in tuberculosis in 7 countries of the Eastern Mediterranean Region. Infect Dis Clin Pract 2008; 16:23-35.

12. Nasehi M, Hassanzadeh J, Rezaianzadeh A, Zeigami $\mathrm{B}$, Tabataee H, Ghaderi E. Diagnosis delay in smear positive tuberculosis patients. J Res Med Sci 2012; 4:1001-1004.

13. Huong NT, Vree M, Duong BD, Khanh VT, Loan VT, Co $N V$, etal. Delays in the diagnosis and treatment of tuberculosis patients in Vietnam: A cross sectional study. BMCPubl Health 2007; 7:110.

14. Ukwaja KN, Alobul, Nweke CO, Oneyenwe EC. Healthcare seeking behavior, treatment delays and its determinants among pulmonary tuberculosis patients in rural Nigeria: A cross sectional study. BMC Health Serv Res 2013; 13;25.

15. Saqib MAN, Awan IN, Rizvi SKA, Shahzad MI, Mirza ZS, Tahseen $S$, etal. Delay in diagnosis of tuberculosis in Rawalpindi, Pakistan. BMC Res Notes 2011; 4:165.

16. Qureshi SA, Morkve O, Mustafa T. Patient and health system delays: Health-care seeking behavior among pulmonary tuberculosis patients in Pakistan. $\mathrm{J}$ Pak Med Assoc 2008; 58:318-321. 
The truth is the truth, even if no one believes it.

A lie is a lie, even if everyone believes it.

\section{- Unknown -}

\section{AUTHORSHIP AND CONTRIBUTION DECLARATION}

\begin{tabular}{|c|l|l|l|}
\hline Sr. \# & \multicolumn{1}{|c|}{ Author-s Full Name } & \multicolumn{1}{|c|}{ Contribution to the paper } & Author=s Signature \\
\hline 1 & Iram Nawaz & 1st Author \\
\hline 3 & Rabia Arshed Usmani & 2nd Author Supervisor \\
\hline 4 & Taskeen Zahra & 3rd Author \\
\hline 5 & Shahbaz Baig & 4th Author \\
\hline
\end{tabular}

